\title{
Immunology of Injectable Collagen in Human Subjects
}

FRANK DELUSTRO, PH.D.

VICTORIA MACKINNON, B.S.

NEIL A. SWANSON, M.D.

\begin{abstract}
Associated with the use of Zyderm Collagen Implant (ZCI) for soft tissue augmentation, the rate of localized hypersensitivity reactions to the initial test injection of ZCI range from $3.0-3.5 \%$ in the literature, and subsequent reactions to treatment have reportedly ranged from $1.1-5.0 \%$. The inflammatory symptoms to the Collagen Test Implant occur within 72 hours in $2 \%$ of those injected, indicating a preexisting sensitivity to bovine collagen in this healthy population. Most adverse treatment reactions follow the first treatment and after injection of $<5 \mathrm{ml}$ of collagen. Furthermore, antibodies against collagen in sera of subjects reporting localized symptoms of hypersensitivity at test or treatment sites are specific for bovine interstitial collagens and show no cross-reactivity with human collagens. Thus, immunologic reaction to $\mathrm{ZCI}$ results in antibovine collagen antibodies and localized inflammatory symptoms in those few subjects who experience hypersensitivity to test or treatment.

Glutaraldehyde cross-linked Zyplast Implant (ZI), has demonstrated a lower incidence of hypersensitivity reactions than ZCI. In examining patients tested with $\mathrm{ZI}$ or treated for intradermal and subdermal indications, we have experienced only 7 hypersensitivity reactions at test sites of $\mathrm{Zl}$, out of 803 tested subjects, and only 3 reactions among 498 treated patients. Therefore, ZI appears to induce a lower incidence of hypersensitivity reactions than $\mathrm{ZCl}$ in man.
\end{abstract}

Frank DeLustro, Ph.D., and Victoria Mackinnon, B.S., are from the Clinical Sciences Section, Collagen Corporation, Palo Alto, California.

Neil A. Swanson, M.D., is from the Department of Dermatology, School of Medicine, University of Michigan, Ann Arbor, Michigan.

Address reprint requests to Neil A. Swanson, M.D., University of Michigan Hospitals, 1500 East Medical Center Drive, Ann Arbor, MI 48109.

\section{INTRODUCTION}

The extensive utilization of collagen-based biomaterials for hemostatic devices, sutures, heart valve replacements, and vascular substitutes is based on its strong biocompatibility and weak immunogenicity. ${ }^{1-3}$ In the search for an injectable material for augmentation of soft tissue contour defects due to scars, rhytids, and genetic deformities, Knapp et al. ${ }^{4}$ demonstrated the successful use of type I collagen-the major natural structural component of the dermis-in such clinical indications. Purified, injectable bovine collagen $(\mathrm{ZCI})$ has proved to be a valuable biomaterial for these indications. ${ }^{5-7} \mathrm{Clini}-$ cal use of injectable collagen has demonstrated a low incidence of hypersensitivity reactions to this bovine collagen. ${ }^{8}$

Glutaraldehyde cross-linked collagen has been associated with further reductions in immunogenicity as evidenced by enhanced biocompatibility of xenogeneic implants. ${ }^{9,10}$ We have begun to examine injectable cross-linked bovine collagen for soft tissue augmentation in man. These immunologic experiences are summarized here.

\section{MATERIALS AND METHODS}

\section{Injectable Collagen}

Zyderm Collagen Implant (ZCI) was prepared from bovine hide as previously described ${ }^{4,5}$ and was utilized as a sterile, fibrillar suspension in phosphatebuffered saline at $\mathrm{pH} 7.2$ at 35 or $65 \mathrm{mg} / \mathrm{ml}$. ZI was also prepared from purified bovine collagen as described in detail by McPherson et al. ${ }^{11}$ and used as a $35 \mathrm{mg} / \mathrm{ml}$ suspension in phosphate-buffered saline at $\mathrm{pH} 7.2$. 


\section{ZCI Clinical Us'}

Data on patients tested intradermally with $0.1 \mathrm{ml}$ $\mathrm{ZCI}$ in the volar forearm and treated with $\mathrm{ZCI}$ for soft tissue contour defects were gathered from the multicenter clinical studies performed, ${ }^{8}$ including 9,427 tested subjects and 5,109 treated patients. Additional data have been gathered on patients treated with ZCI during four years (7/81-6/85) of postmarketing. During this time approximately 200,000 patients were treated with ZCI domestically, as determined by the volume of $\mathrm{ZCI}$ sold in the United States. Definitions of adverse reactions have been detailed previously."

\section{Zl Clinical Use}

Data presented here on people tested or treated with ZI were gathered in controlled clinical trials conducted under the Investigational Device Exemption rules of the U.S. Food and Drug Administration, and with appropriate Institutional Review Board-approved informed consent from participating subjects. In the Sensitivity Study, human volunteers were injected intradermally with a $0.1-\mathrm{ml}$ test dose of $\mathrm{ZI}$ in the volar forearm. The test site was observed for hypersensitivity and sera were obtained both before injection and at intervals detailed in the text. Additional patient data have been obtained from patients under study for the subdermal treatment of keratoses of the feet, intradermal treatment of soft tissue defects, and subdermal treatment of contour irregularities with ZI. Localized hypersensitivity reactions were defined as erythema, induration, and/or pruritus, as well as antibodies against bovine collagen.

\section{Antibody Assays}

Radioimmunoassay (RIA) for antibodies against collagen has been described in detail previously. ${ }^{12}$
The Enzyme-Linked Immunosorbent Assay (ELISA) was performed as previously described. ${ }^{13}$ In addition to a conjugate of wide antibody class specificity, ${ }^{13}$ peroxidase-labeled rabbit antihuman $\operatorname{IgG}, \lg A$, or IgM antibody conjugates were utilized to measure class-specific antibody activities. These techniques provide sensitive and specific mechanisms to examine anticollagen humoral immune responses.

\section{RESULTS AND DISCUSSION}

Following the extensive use of $\mathrm{ZCI}$ for the clinical treatment of dermal contour defects, several publications have appeared 8.14 ith that examine the rate of hypersensitivity to test and treatment (Table 1 ). The response to test ranges from $3.0 \%$ in a study of 9,427 subjects by Cooperman et al. ${ }^{\circ}$ and $3.1 \%$ in a study of 7,000 subjects by Castrow and Krull, ${ }^{14}$ to $3.5 \%$ in an investigation of 300 patients by Kamer and Churukian. "5imilarly, these studies ${ }^{8,14,15}$ have reported treated site adverse reaction rates of $1.1-1.5 \%$, while another report ${ }^{16}$ has indicated a higher incidence $(5.0 \%)$ in 202 patients (Table 1). These differences may be related to the number of patients examined, the specific demographics of the study populations, or the clinical interpretation of symptoms of hypersensitivity.

In a study of reactions to skin test implantation of $\mathrm{ZCI},{ }^{8}$ the time of onset of the symptoms provides a useful insight into the presence of sensitivity to bovine collagen in the healthy population. In Figure 1 , it can be seen that $70 \%$ of the hypersensitivity responses to test implantation (first exposure) with $\mathrm{ZCI}$ occur within 72 hours, and the data suggest a preexisting immunity to bovine collagen in these subjects. Of the remaining test site reactions, approximately $10 \%$ take place from 3-7 days, and the

TABLE 1

Localized Hypersensitivity Reactions to Zyderm Collagen Implant

\begin{tabular}{cccc}
\hline & Hypersensitivity Response & Number of Patients \\
Reference & Following: & Followed & Incidence \\
Cooperman $(1985)^{4}$ & Test Injection & 9,427 & $3.0 \%$ \\
& Treatment & 5,109 & $1.1 \%$ \\
Siegle $(1984)^{\text {in }}$ & Treatment & 202 & $5.0 \%$ \\
Kamer $(1984)^{15}$ & Test Injection & 300 & $3.5 \%$ \\
& Treatment & 300 & $1.3 \%$ \\
Castrow $(1983)^{1.4}$ & Test Injection & 7.000 & $3.1 \%$ \\
& Treatment & 7.000 & $1.5 \%$ \\
\hline
\end{tabular}


remainder develop over approximately 1 month. It is of interest to note the presensitization, presumably through dietary exposure to collagen, of approximately $2 \%$ of the prospective patient pool, which represents a healthy population; in addition, antibodies to bovine collagen have been demonstrated in the sera of 1-8\% of uninjected, healthy controls. ${ }^{17,18}$ The data suggest that those subjects who are a high responder genotype produce antibodies rapidly in vivo to a minimal antigenic exposure, such as through environmental exposure or the Collagen Test Implant, and as these subjects are detected after early exposures, late sensitizations are infrequently encountered. ${ }^{8,18}$

Of the patients who are treated with $\mathrm{ZCI}$, hypersensitivity reactions can occur..$^{8,14-16}$ In a multicenter clinical study of 5,109 treated patients, ${ }^{8}$ it was found that increasing total volumes of $\mathrm{ZCI}$ utilized to treat these patients was not found to result in an increasing incidence of hypersensitivity ( $\mathrm{Ta}-$ ble 2). Hypersensitivity reactions were observed in $1.6 \%$ of patients treated with $<5 \mathrm{ml}$, and exposure to larger volumes did not increase the incidence of sensitization to the implant material (Table 2). These results can be better understood in view of the incidence of hypersensitivity reactions following treatment relative to the number of treatment sessions (Fig. 2). In examining over 852 treatment site reactions in the estimated 200,000 patients treated with ZCI in the United States from July 1981 to June 1985, most hypersensitivity $(56 \%)$ followed the first treatment with $\mathrm{ZCI}$, and $28 \%$ followed the second treatment. These data indicate that most hypersensitivity reactions to bovine collagen take place after the earliest exposures (test and first treatment), and subsequent treatments with $\mathrm{ZCI}$
Inflammatory Srmptoms at Test Sites of ZTIERM Collagen

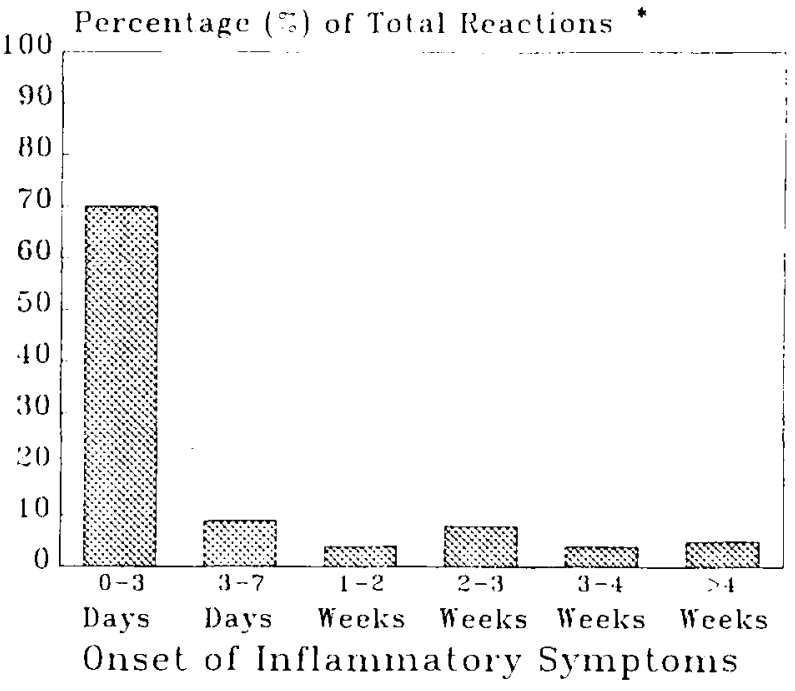

* Responses $(n=28.4)$ reported to Collagen Corporation during controlled clinical trials with 9427 patients.

FIGURE 1. During a prospective study of 9,427 patients who received an intradermal test injection of ZCI, 284 subjects experienced adverse reactions and the onset of inflammatory symptoms at test sites. The onset times of these reactions were monitored, and the results are expressed as the percentage of the total reactions $(n=284)$ reported with increasing time following injection.

have significantly diminished potential for eliciting a hypersensitivity response in situ (Fig. 2). Together, these findings (Figs. 1 and 2, Table 2) demonstrate that, in those subjects who display hypersensitivity to bovine collagen, sensitization to ZCI usually takes place after initial exposures to mini-

TABLE 2

Adverse Reactions Against Zyderm Collagen Implant According to Volumes Injected ${ }^{\mathrm{a}}$

\begin{tabular}{|c|c|c|c|}
\hline $\begin{array}{l}\text { Total }^{\mathrm{b}} \\
\text { Treatment } \\
\text { Volume }\end{array}$ & $\begin{array}{l}\text { Number } \\
\text { of Patients } \\
\text { Treated }\end{array}$ & $\begin{array}{c}\text { Number of } \\
\text { Patients with } \\
\text { Adverse Reactions }\end{array}$ & $\begin{array}{c}\text { Incidence of } \\
\text { Adverse Reactions }\end{array}$ \\
\hline$<5 \mathrm{ml}$ & 3,885 & 62 & $1.6 \%$ \\
\hline $5-9.9 \mathrm{ml}$ & 845 & 4 & $0.5 \%$ \\
\hline $10-29 \mathrm{ml}$ & 355 & 1 & $0.3 \%$ \\
\hline $30-49 \mathrm{ml}$ & 19 & 0 & 0 \\
\hline $50-100 \mathrm{ml}$ & 4 & 0 & 0 \\
\hline$\geq 100 \mathrm{ml}$ & 1 & 0 & 0 \\
\hline All & 5,109 & $\overline{67^{\circ}}$ & $\overline{1.3 \%}$ \\
\hline
\end{tabular}

${ }^{a}$ Data were collected by the Collagen Corporation during controlled clinical trials with 5,109 treated subjects. ${ }^{8}$

bTotal amount of $\mathrm{ZCl}$ injected per patient during the entire course of treatment.

This group of patients includes subjects $(n=27)$ who were treated following an unreported positive test reaction. 


\section{Treatment Site Reactions To ZYDERM ${ }^{\mathbb{R}}$ Collagen Relative to Number of Treatments}

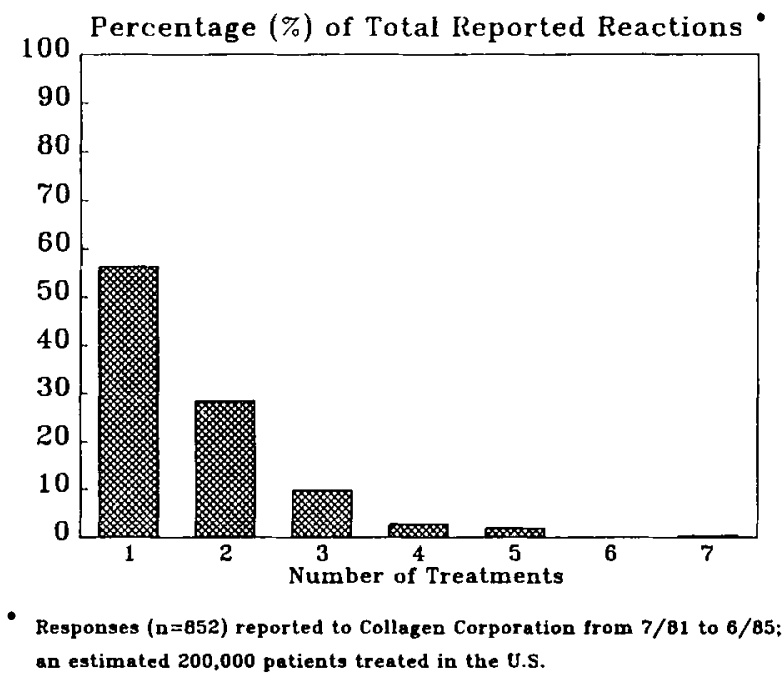

FIGURE 2. From $7 / 81$ to $6 / 85,852$ patients reportedly experienced hypersensitivity reactions to $\mathrm{ZCI}$ out of a population of approximately 200,000 treated patients. The data are expressed as the percentage of the total reactions ( $\mathrm{n}=852$ ) occurring after the last reported treatment session.

mal volumes of material; repeated treatment with significant volumes of $\mathrm{ZCI}$ does not increase the incidence of hypersensitivity.

It has been reported that hypersensitivity to $\mathrm{ZCI}$ can be monitored accurately by examining circulating antibodies to bovine collagen. ${ }^{12,13,16-18}$ As demonstrated in Table 3, localized hypersensitivity reactions at sites of treatment with ZCI are associated with the detection of circulating antibodies against $\mathrm{ZCI}$ as measured by the ELISA or RIA, while systemic reports (such as malaise, arthralgia, and swelling) without localized symptoms have not been found to be associated with detectable antibodies against bovine collagen. However, no sig-

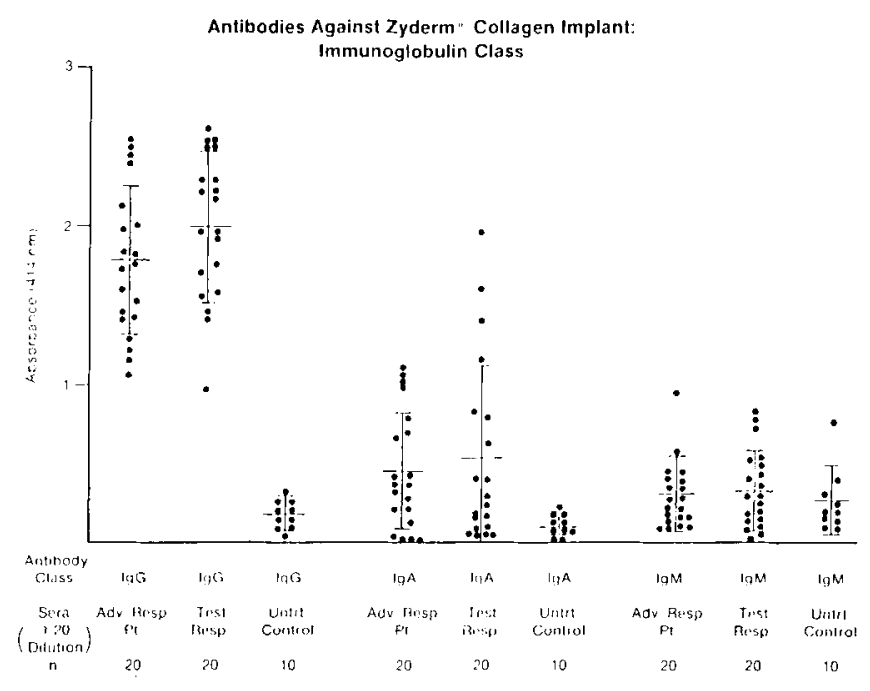

FIGURE 3. Sera from patients experiencing adverse reactions at test sites (Tet Resp.) or treatment sites (Adv. Resp. Pt.), as well as untreated controls (Untrt. Control), were examined in the ELISA for $\operatorname{IgG}, A$, and $M$ antibodies against $\mathrm{ZCI}$. All sera were assayed in duplicate at a 1:20 dilution. Data are expressed as the absorbance values for all sera tested; for each group, the mean absorbance $\pm S D$ is indicated by solid bars.

nificant reactivity is observed against human interstitial collagens, ${ }^{13,18}$ and only infrequent, weak cross-reaction is observed against guinea pig or rat type I collagen. ${ }^{13}$ As previously described, ${ }^{17}$ anticollagen antibodies are predominantly $\operatorname{IgG}$ and are found to the same extent in sera of patients reacting against a test or treatment with ZCI (Fig. 3). In addition, while IgG is the predominant antibody class observed, sera from some adverse response patients demonstrate circulating IgA anticollagen antibodies (Fig. 3) when compared to control sera from unexposed subjects; IgM antibodies against $\mathrm{ZCI}$ are not present. The presence of antibodies to bovine collagen has also been demonstrated in sera

TABLE 3

Development of Antibodies Against Zyderm Collagen Implant in Sera of Patients Experiencing a Localized Treatment Site Response but not with Systemic Complaints

\begin{tabular}{|c|c|c|c|c|}
\hline \multirow[b]{2}{*}{ Reaction Site } & \multirow[b]{2}{*}{$\begin{array}{c}\text { Number of Patients } \\
\text { Examined }\end{array}$} & \multicolumn{3}{|c|}{ Anti-ZCI Antibodies ${ }^{\text {a }}$} \\
\hline & & $\begin{array}{c}\text { Positive } \\
+\end{array}$ & $\begin{array}{l}\text { Equivocal } \\
+1-\end{array}$ & Negative \\
\hline Treatment Site & 93 & $\begin{array}{c}82^{\mathrm{b}} \\
(88.2 \%)\end{array}$ & $\begin{array}{c}4 \\
(4.3 \%)\end{array}$ & $\begin{array}{c}7^{\mathrm{b}} \\
(7.5 \%)\end{array}$ \\
\hline Systemic Only & 25 & $\begin{array}{l}0^{\mathrm{b}} \\
(0 \%)\end{array}$ & $\begin{array}{c}3 \\
(12.0 \%)\end{array}$ & $\begin{array}{c}22^{\mathrm{b}} \\
(88.0 \%)\end{array}$ \\
\hline
\end{tabular}

'Sera examined by RIA or ELISA

bhi-squared: $p<0.001$ 
of patients without symptoms of hypersensitivity after treatment with $\mathrm{ZCI}$ but in this case they do not appear to have any clinical significance. ${ }^{17}$ Thus, hypersensitivity to $\mathrm{ZCI}$, as measured through circulating anticollagen antibodies, is associated with IgG antibodies that react with sequential and conformational determinants on bovine interstitial collagens and that demonstrate a species specificity for bovine collagen.

Results from studies with glutaraldehyde-treated xenografts and allografts have indicated a minimal host response and prolonged graft survival. ${ }^{9,10,19-21}$ These data in animals and human subjects have demonstrated the potential value of cross-linked dermal grafts. ${ }^{9,10,19}$ In initial studies with crosslinked ZI in which 246 volunteers received skin tests, no circulating antibodies to bovine collagen were detected at 1 or 2 months after injection as compared to pretreatment control sera (Table 4). Even when subjects were examined at approximately 6 or 12 months following exposure to the test dose, no follow-up serum was found to possess anticollagen antibody activity when compared to matched pretreatment control serum from the same subject (Table 4). Pretreatment and follow-up sera from only one subject displayed significant binding to ZCI. The absence of elevated levels of anticollagen antibodies in the sera of these subjects during the follow-up period suggests a lower level of reactivity than the $3 \%$ of subjects who react to a skin test of ZCI (Table 1).

In ongoing clinical investigations with $\mathrm{ZI}$ for the intradermal and subdermal treatment of soft tissue defects, the results suggest that the expected incidence of hypersensitivity to both test and treatment

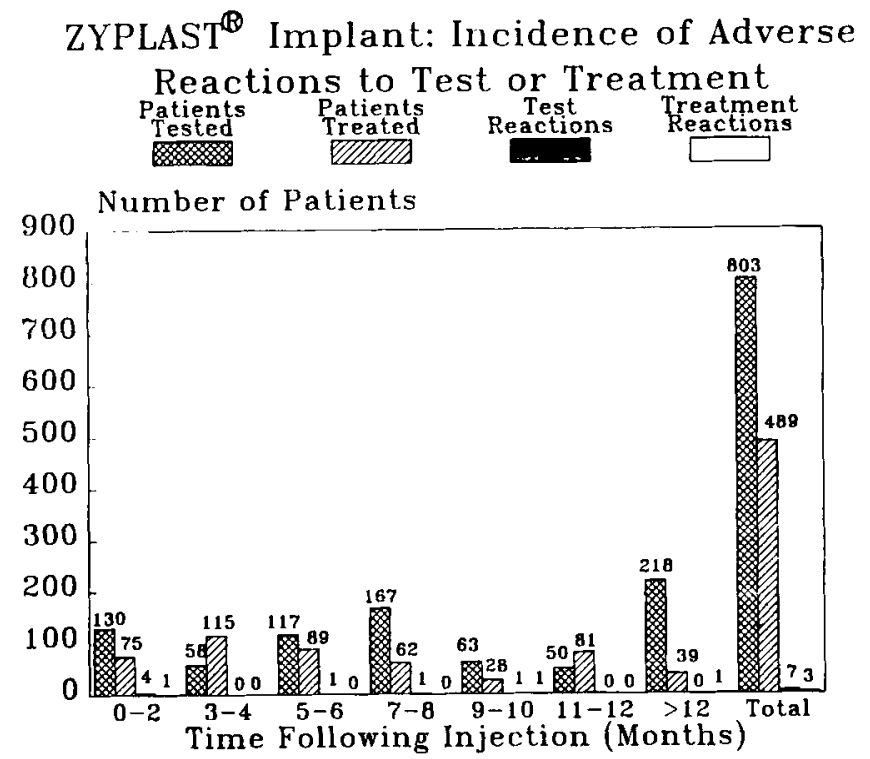

FIGURE 4. Patients received test or treatment injections of Zyplast Implant as described in the text. The total number of patients injected at test or treatment sites is indicated at the last time they were clinically examined to date. Onset of adverse responses is demonstrated by the number of patients having test or treatment site reactions and the time they were first reported. The data are expressed in months following the test injection or following the last treatment implantation for each patient. Numbers above each bar represent the exact number of patients per group.

is significantly lower than that observed with $\mathrm{ZCI}$. In these studies and the sensitivity study previously discussed, we have tested 803 subjects with $\mathrm{ZI}$ and followed up 498 patients for $>6$ months (Fig. 4). The finding of only 7 patients with adverse test site reactions of inflammation and immunity

TABLE 4

Summary of Immunologic Results in Zyplast Implant Sensitivity Studies in Human Volunteers

\begin{tabular}{|c|c|c|c|c|}
\hline \multirow[b]{2}{*}{ Group $^{a}$} & \multirow[b]{2}{*}{ Sera Source } & \multirow{2}{*}{$\begin{array}{c}\text { Number of } \\
\text { Patients Examined }\end{array}$} & \multicolumn{2}{|c|}{ ELISA Results $^{b}$} \\
\hline & & & Zyplast Implant & Zyderm Collagen \\
\hline \multirow[t]{2}{*}{ I } & Pretreatment & 138 & $0.151 \pm 0.072$ & $0.096 \pm 0.058$ \\
\hline & 4-week follow-up & 138 & $0.151 \pm 0.077$ & $0.091 \pm 0.060$ \\
\hline \multirow[t]{2}{*}{ II } & Pretreatment & 48 & $0.092 \pm 0.061$ & $0.078 \pm 0.051$ \\
\hline & 4-week follow-up & 48 & $0.085 \pm 0.056$ & $0.083 \pm 0.051$ \\
\hline \multirow[t]{2}{*}{ III } & Pretreatment & 60 & $0.254 \pm 0.113$ & $0.138 \pm 0.075$ \\
\hline & 8-week follow-up & 60 & $0.245 \pm 0.123$ & $0.145 \pm 0.097$ \\
\hline \multirow[t]{2}{*}{ I \& II } & Pretreatment & $131^{\mathrm{c}}$ & $0.057 \pm 0.039$ & $0.020 \pm 0.016$ \\
\hline & 6-week follow-up & 132 & $0.056 \pm 0.042$ & $0.021 \pm 0.020$ \\
\hline \multirow[t]{2}{*}{ I \& II } & Pretreatment & $126^{\mathrm{d}}$ & $0.143 \pm 0.055$ & $0.081 \pm 0.089$ \\
\hline & 12-month follow-ups & 131 & $0.145 \pm 0.054$ & $0.085 \pm 0.078$ \\
\hline
\end{tabular}

${ }^{a}$ Groups I-III represent separately-enrolled study groups at different times.

bata are expressed as the mean absorbance \pm SD for 1:20 dilutions of sera.

cPretreatment serum from one subject was not available.

${ }^{\mathrm{d}}$ Pretreatment sera from five subjects were not available. 
against collagen indicates a reaction rate of $0.9 \%$ (7/803) to injection with a test dose of $\mathrm{ZI}$, as compared to the $3-3.5 \%$ observed with ZCI (Table 1). As seen in Figure 4, 489 subjects have been treated with $Z I$, and 210 have been examined at $>6$ months following exposure. Only 3 adverse treatment reactions with immunity against collagen have been observed, for an incidence to date of $0.6 \%$ (3/489), and two of these have occurred at $>6$ months following treatment $(2 / 210,1.0 \%)$. The current data suggest that the immunogenicity of $\mathrm{ZI}$ is reduced below that found with ZCI (Table 1).

\section{CONCLUSION}

For many decades, millions of patients have benefited from treatment with collagen-derived sutures, hemostatic agents, vascular prostheses, and injectable fibrillar collagen. The presence of naturally occurring antibodies to collagen has been reported in healthy human control populations ${ }^{17,23-25}$ but collagen-derived biomaterials have nonetheless proved to be of great clinical value and of minimal immunogenicity. ${ }^{1-3}$ Injectable bovine collagen has provided a valuable clinical alternative for the treatment of dermal contour defects with few adverse events. ${ }^{4-7}$

When these adverse reactions do occur at test or treatment sites, they can be characterized histologically as localized hypersensitivity reactions that demonstrate the local accumulation of a lymphohistiocytic infiltrate. ${ }^{26}$ This picture of an immune reaction is accompanied by the detection of circulating antibodies against bovine collagen in $90-100 \%$ of these patients. ${ }^{12,13,17,18}$ Antibody activity against $\mathrm{ZCI}$ is associated clinically with local hypersensitivity reactions, not with systemic complaints (Table 3 ). These antibodies have been well characterized, and while reacting with native or denatured bovine interstitial collagen, they do not cross-react with human collagen. ${ }^{12,13,18}$ Levels of circulating antibodies are similar in patients with hypersensitivity reactions following test or treatment with $\mathrm{ZCI}$. Immunoblotting techniques have demonstrated binding of these antibodies to multiple antigenic determinants in $\mathrm{ZCI}{ }^{17}$ Extensive mapping for reactivity with cyanogen bromide peptides of $\alpha 1(\mathrm{I})$ and $\alpha 2(\mathrm{I})$ chains of bovine type I collagen has verified this heterogeneity and identified $\alpha 1-C B 6$ and $\alpha 2-C B 4$ as major antigenic determinants on the denatured molecule. ${ }^{13}$ This anti- $\mathrm{ZCI}$ reaction is best characterized as an immune response against bovine collagen that does not crossreact with collagens of other unrelated species. ${ }^{8,13,18}$
While little direct immunologic data are available on the immunogenicity of cross-linked collagen, the absence of significant clinical or histologic signs of a local hypersensitivity response $\mathrm{e}^{9,10,19-21}$ suggests that there is minimal recognition by the host. Clinical experience with $\mathrm{ZI}$ indicates that this assumption is correct. ${ }^{22}$ Elson ${ }^{22}$ has described hypersensitivity reactions at sites of $\mathrm{ZCI}$ only in patients treated with both $\mathrm{ZCI}$ and $\mathrm{ZI}$; in these patients, the $Z I$-injected sites did not react. In this description of clinical experience in over 180 patients treated with ZI, none of the 62 patients treated with ZI alone experienced hypersensitivity reactions. Data from numerous studies in clinical trials and postmarketing use have shown that the incidence of hypersensitivity to ZI compares favorably to ZCI. These results provide further evidence that glutaraldehyde cross-linked (Zyplast) collagen possesses less immunogenicity than its untreated counterpart $(\mathrm{ZCI})$. The potential utility of Zyplast Implant in soft tissue reconstruction is evident.

\section{REFERENCES}

1. Chvapil M, Kronenthal RL, VanWinkle YW. Medical and surgical applications of collagen. Int Rev Connect Tiss Res 6:1-61, 1973.

2. Stenzel K, Miyata T, Rubin A. Collagen as a biomaterial. Ann Rev Biophys Bioeng 3:231-253, 1974.

3. Pharriss BB. Collagen as a biomaterial. J Am Leather Chemists Assoc 75:474-480, 1980.

4. Knapp, TR, Kaplan EN, Daniels JR. Injectable collagen for soft tissue augmentation. Plast Reconstr Surg 60:398-405, 1977.

5. Knapp TR, Vistnes LM. The augmentation of soft tissue with injectable collagen. Sym Horiz Plast Surg 12:221-225, 1985.

6. Matton G, Anseeuw A, DeKeyser F. The history of injectable biomaterials and the biology of collagen. Aesth Plast Surg 9:133-140, 1985

7. Kaplan EN, Falces E, Tolleth H. Clinical utilization of injectable collagen. Ann Plast Surg 10:437-451, 1983.

8. Cooperman LS, Mackinnon V, Bechler G, Pharriss BB. Injectable collagen: A six-year clinical investigation. Aesth Plast Surg 9:145-151, 1985.

9. Oliver RF, Grant RA, Cox RW, Cooke A. Effect of aldehyde cross-linking of human dermal collagen implants in the rat. Br J Exp Pathol 61:544-549, 1980.

10. Griffiths RW, Shakespeare PG. Human dermal collagen allografts: A three-year histological study. Br J Plast Surg 35:519-523, 1982.

11. McPherson JM, Ledger PW, Sawamura S, et al. A physicochemical characterization of an injectable glutaraldehyde cross-linked collagen implant. J Biomed Mat Res 20:79-92, 1986.

12. Cooperman LS, Michaeli D. The immunogenicity of injectable collagen, II: A retrospective review of seventy-two tested and treated patients. J Am Acad Dermatol 10:647-651, 1984.

13. Ellingsworth LR, DeLustro F, Brennan JE, et al. The human 
immune response to reconstituted bovine collagen. J Immunol 136:877-882, 1986.

14. Castrow II FF, Krull EA. Injectable collagen implant-Update. J Am Acad Dermatol 9:889-893, 1983.

15. Kamer FM, Churukian MM. Clinical use of injectable collagen: A three-year retrospective study. Arch Otolaryngol 110:93-98, 1984.

16. Siegle RJ, McCoy Jr. JP, Schade W, Swanson NA. Intradermal implantation of bovine collagen: Humoral immune responses associated with clinical reactions. Arch Dermatol 120:183-187, 1984.

17. McCoy Jr. JP, Schade WJ, Siegle RJ, et al. Characterization of the humoral immune response to bovine collagen implants. Arch Dermatol 121:990-994, 1985.

18. DeLustro F, Smith S, Sundsmo J, et al. Reaction to injectable collagen: Results in animal models and clinical use. Plast Reconstr Surg 79:581-592, 1987.

19. Schechter I, Belledgrin A, Ben-Basat M, Kaplan I. Prolonged retention of glutaraldehyde-treated skin homografts in humans. Br J Plast Surg 28:198-202, 1975.

20. Carpentier A, Deloche A, Relland J, et al. Six-year follow- up of glutaraldehyde-preserved heterografts with particular reference to the treatment of congenital valve malformations. J Thorac Cardiovasc Surg 68:771-781, 1974.

21. Horowitz MS, Goodman DJ, Fogarty TJ, Harrison DC. Mitral valve replacement with glutaraldehyde-preserved porcine heterografts: Clinical hemodynamic and pathological correlations. J Thorac Cardiovasc Surg 67:885-895, 1974.

22. Elson M. Clinical assessment of Zyplast Implant: A year of experience for soft tissue contour correction. J Am Acad Dermatol, in press, 1988.

23. Guilbert B, Dighiero G, Avrameas S. Naturally occurring antibodies against nine common antigens in human sera. J Immunol 128:2779-2787, 1982.

24. Grabar P. Autoantibodies and the physiological role of immunoglobulins. Immunol Today 4:337, 1983.

25. Avrameas S, Dighiero G, Lymberi P, Guilbert B. Studies on natural antibodies and autoantibodies. Ann Immunol 134:103, 1983.

26. Barr RJ, Stegman SJ. Delayed skin test reaction to injectable collagen implant (Zyderm): A histopathologic comparative study. J Am Acad Dermatol 10:652-685, 1984. 